\title{
Effects of direct current electric-field using ITO plate on breast cancer cell migration
}

\author{
Min Sung Kim,2, Mi Hee Lee ${ }^{1}$, Byeong-Ju Kwon ${ }^{1,2}$, Hyok Jin Seo ${ }^{1,2}$, Min-Ah Koo ${ }^{1,2}$, Kyung Eun You ${ }^{1,2}$, \\ Dohyun $\mathrm{Kim}^{1}$ and Jong-Chul Park ${ }^{1,2^{*}}$
}

\begin{abstract}
Background: Cell migration is an essential activity of the cells in various biological phenomena. The evidence that electrotaxis plays important roles in many physiological phenomena is accumulating. In electrotaxis, cells move with a directional tendency toward the anode or cathode under direct-current electric fields. Indium tin oxide, commonly referred to as ITO has high luminous transmittance, high infrared reflectance, good electrical conductivity, excellent substrate adherence, hardness and chemical inertness and hence, have been widely and intensively studied for many years. Because of these properties of ITO films, the electrotaxis using ITO plate was evaluated.
\end{abstract}

Results: Under the $0 \mathrm{~V} / \mathrm{cm}$ condition, MDA-MB-231 migrated randomly in all directions. When $1 \mathrm{~V} / \mathrm{cm}$ of dc EF was applied, cells moved toward anode. The $y$ forward migration index was $-0.046 \pm 0.357$ under the $0 \mathrm{~V} / \mathrm{cm}$ and was $0.273 \pm 0.231$ under direct-current electric field of $1 \mathrm{~V} / \mathrm{cm}$. However, the migration speed of breast cancer cell was not affected by direct-current electric field using ITO plate.

Conclusions: In this study, we designed a new electrotaxis system using an ITO coated glass and observed the migration of MDA-MB-231 on direct current electric-field of the ITO glass.

Keywords: Cell migration, Electrotaxis, ITO plate, Breast cancer cell, MDA-MB-231

\section{Background}

In a variety of biological phenomena, cell migration plays a very important role. Cellular migrations are prominent in morphogenic processes ranging from gastrulation to development of the nervous system in embryogenesis. Migration of fibroblasts and vascular endothelial cells is essential for wound healing. In metastasis, tumor cells immigrate from the initial tumor mass into the circulatory system, which they subsequently leave and migrate into a new site. In the inflammatory response, leukocytes migrate into the areas where insult has occurred, and then they affect phagocyte and immune functions. In normal physiology and pathology, migration remains crucial for the adult organism. Finally, cell migration is crucial to technological applications in tissue engineering

\footnotetext{
* Correspondence: parkjc@yuhs.ac

${ }^{1}$ Cellbiocontrol Laboratory, Department of Medical Engineering, Yonsei University College of Medicine, 134 Shinchon-dong, Seodaemun-gu, Seoul 120-752, Korea

${ }^{2}$ Brain Korea 21 PLUS Project for Medical Science, Yonsei University College of Medicine, 134 Shinchon-dong, Seodaemun-gu, Seoul 120-752, Korea
}

and playing an essential role in colonization of biomaterials scaffolding $[1,2]$.

Most organs (especially glands) and embryos surrounded by a layer of epithelial cells produce potential differences or transepithelial potentials (TEPs) of a few millivolts to tens of millivolts. These correspond to transcellular direct-current EFs (dcEFs) of $50-500 \mathrm{mV} / \mathrm{mm}$, as measured in vivo or in vitro in guinea pig trachea, mouse rectum, small airways of sheep lungs and rat prostate. Endogenous EFs might also exist in the central nervous system owing to the presence of extracellular field potentials across the blood-brain barrier, including specific transendothelial [3-9].

The evidence that electrotaxis is very important in many physiological phenomena is accumulating. The cells move with a directional preference toward the cathode or anode under direct-current electric fields (dcEFs) [10-14]. The preferential direction of migration during electrotaxis varies among the cell types and under different experimental conditions.

Indium tin oxide, commonly referred to as ITO, is an n-type semiconductor with a band gap between 3.5 and 


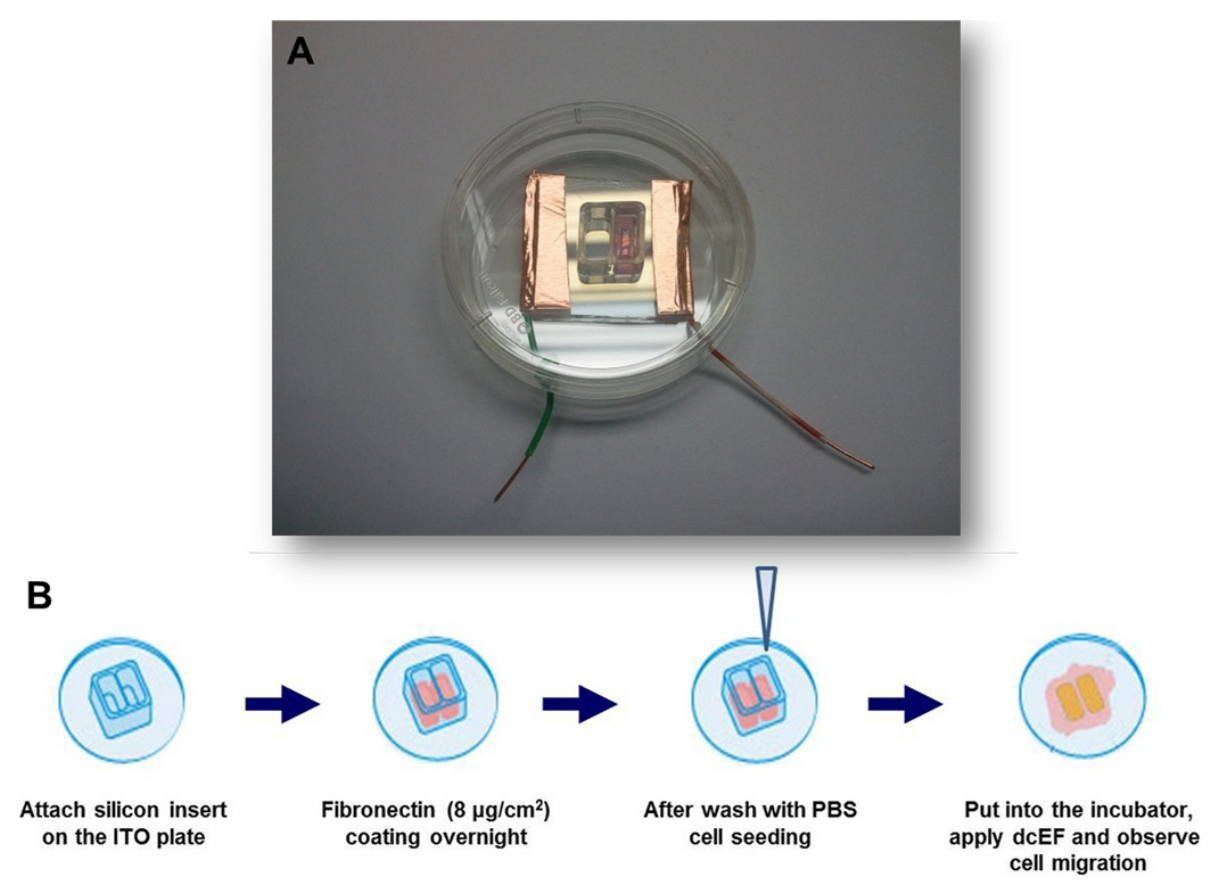

Figure 1 Indium-tin-oxide (ITO) plate electrotaxis system. Indium-tin-oxide (ITO) plate electrotaxis system (A) and Schematic diagram of electrotaxis using ITO plate (B).

$4.3 \mathrm{eV}$ and a maximum charge carrier concentration in the order of $10^{21} \mathrm{~cm}^{-3}$ [15-17]. Consequently, ITO is transparent to visible and near-infrared light and has a low electrical resistivity. ITO films have high luminous transmittance, high infrared reflectance, good electrical conductivity, excellent substrate adherence, hardness and chemical inertness and hence, have been widely and intensively studied for many years [17-20]. Because of these properties, ITO films are extensively used as coating electrodes in optoelectronic devices [21], electroluminescent devices [22], photovoltaic cells [23-25], electrochromic devices [21], liquid crystal displays [21-25], sensors [26], storage-type cathode ray tubes [21], biological devices [27], flat panel display devices and heat reflecting mirrors [28]. In this study, we designed a new electrotaxis system using an ITO glass where DC current flows on and observed the migration of MDA-MB-231 under this system.

\section{Methods}

\section{Cell culture}

MDA-MB-231 were purchased from ATCC (Rockville, MD, USA) and maintained in Dullbecco's modification of eagle's minimal essential medium (DMEM) supplemented with $10 \%$ fetal bovine serum (FBS, Lonza) and $1 \%$ antibiotics. Cells were incubated at $37^{\circ} \mathrm{C}$ in $5 \% \mathrm{CO}_{2}$ atmosphere and the medium was changed every 2-3 days. Cells

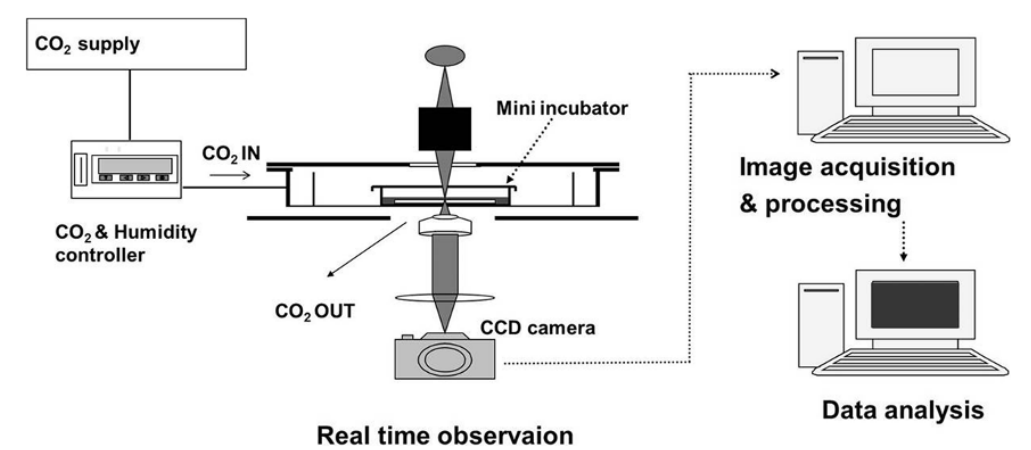

Figure 2 Real time observation system. Schematic diagram of the real time observation system for the evaluation of cell migration. 

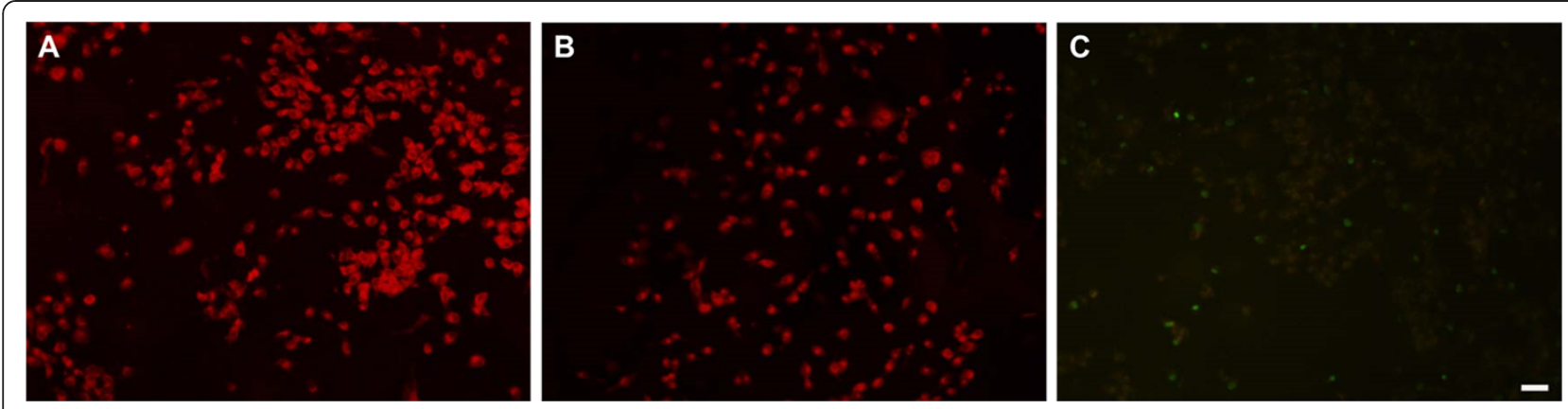

Figure 3 LIVE/DEAD assay of MDA-MB-231. LIVE/DEAD assay of MDA-MB-231 in an EF of $0 \mathrm{~V} / \mathrm{cm}$ (A), $1 \mathrm{~V} / \mathrm{cm}$ (B) and $2 \mathrm{~V} / \mathrm{cm}$ (C). (Scale bar = $100 \mu \mathrm{m})$.

were subcultured with $0.25 \%$ trypsin/EDTA when they reach $50 \sim 70 \%$ confluence.

\section{ITO plate electrotaxis system}

Electrotaxis system using Indium-Tin-Oxide coated glasses were designed for currents contact cells directly. IndiumTin-oxide (ITO) coated glasses were kindly provided by Kwangwoon University and were cut with approximately dimensions $2 \times 2 \mathrm{~cm}^{2}$. Cu tape ( $3 \mathrm{M}$, USA) connected both ends of $2 \times 2 \mathrm{~cm}^{2}$ cut ITO coated glasses (ITO plate) with $5 \mathrm{~cm}$ long electric wire, then the ITO plate was dipped into $70 \%$ ethanol for 30 minutes. The sterilized grease were pasted to one side of the silicon culture insert (Ibidi, Munchen, Germany), then put the silicon insert on the ITO coated glass surface (Figure 1A).

\section{Electrotaxis of MDA-MB-231on ITO plate}

Fibronectin needed to be coated on the surface of ITO plate for MDA-MB-231 cell attachment. Add $50 \mu \mathrm{l}$ of fibronectin solutions $\left(8 \mu \mathrm{g} / \mathrm{cm}^{2}\right)$ to silicon insert and incubate overnight at $37^{\circ} \mathrm{C}$. Cells $\left(8 \times 10^{3}\right.$ cells $\left./ \mathrm{cm}^{2}\right)$ were seeded and allowed to grow for at least 24 hours in DMEM supplement with $10 \% \mathrm{FBS}, 1 \%$ anti-biotics at $37^{\circ} \mathrm{C}$ in a $5 \% \mathrm{CO}_{2}$ incubator (Figure $1 \mathrm{~B})$. Immediately before a test, medium was replaced with DMEM supplemented with 10\% FBS, $1 \%$ antibiotics. Cells were exposed to a direct-current electric field for 3 hours as indicated at $37^{\circ} \mathrm{C}$ in a temperature-controlled chamber on an inverted microscope stage.

\section{Cell viability assay}

Cell viability was measured using LIVE/DEAD assay kit (Invitrogen, CA, USA). After electric field treatment, cells
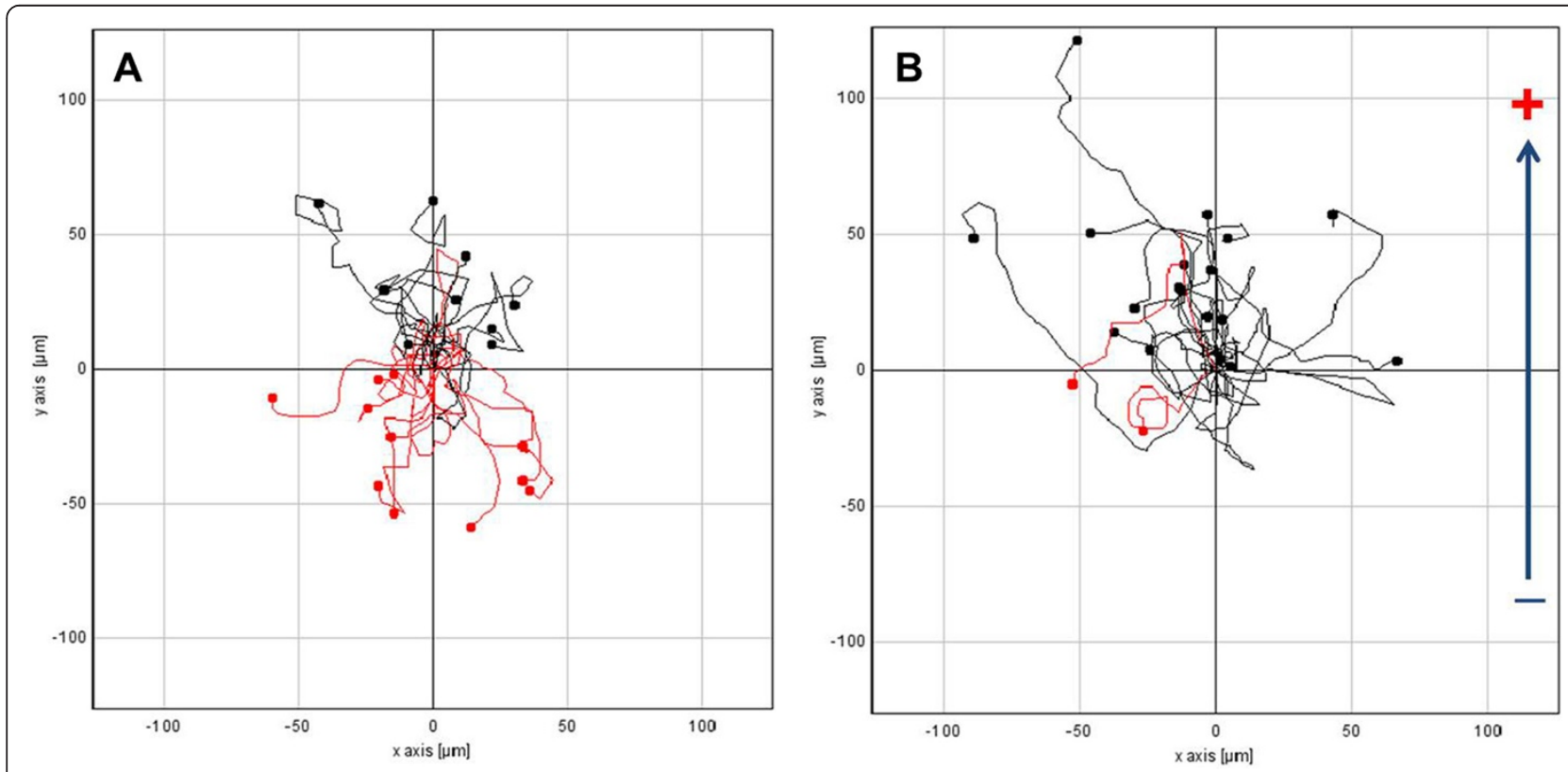

Figure 4 Cell tracking image of MDA-MB-231. Cell tracking image of MDA-MB-231 in an EF of $0 \mathrm{~V} / \mathrm{cm}$ (A), $1 \mathrm{~V} / \mathrm{cm}$ (B). 
were washed 2 times with PBS, then they treated with resazurin $5 \mu \mathrm{M}$ and SYTOX Green $0.1 \mu \mathrm{M}$ in dark room. Cells were incubated in $\mathrm{CO}_{2}$ incubator for 15 minutes and The ITO plate were observed by a fluorescence inverted microscope.

\section{Time-lapse phase contrast microscopy and analysis of cell migration}

We used the real time observation system (Figure 2) to observe the migration of the cells on the ITO plate. The real time observation system consisted of incubator system installed with the microscope to observe live cells migration. The incubator was regulated by temperature and gas composition controlling program (CCP ver. 3.8, Live Cell Instrument, Korea) under proper environment for cell $\left(\mathrm{CO}_{2} 5 \%, 37^{\circ} \mathrm{C}\right)$.

\section{Image acquisition}

The cells were cultured in the electrotaxis incubator placed on the microscope stage, and cell images were recorded every 5 minutes until electric treatment ends by the change-coupled device (CCD) camera (Electric Biomedical Co. Ltd., Osaka, Japan) attached to the inverted microscope (Olympus Optical Co. Ktd., Tokyo, Japan). Images were conveyed directly from a frame grabber to computer storage using Tomoro image capture program and saved them as JPEG image files.

\section{Cell tracking and evaluation of cell migration}

For data analysis, captured images were imported into Image J (ImageJ $1.37 \mathrm{v}$ by $\mathrm{W}$. Rusband, National Institutes of Health, Baltimore, Md). Image analysis was carried out by manual tracking and chemotaxis tool plug-in (v. 1.01, distributed by ibidi $\mathrm{GmbH}$, Munchen, Germany) in ImageJ software. We obtained the datasets of $\mathrm{XY}$ coordinates by using manual tracking, then these datasets were imported into chemotaxis plug-in. This tool computed the cell migration speed and $y$ forward migration index (y FMI) of cells and plotted the cell migration pathway. The migration speed was calculated as an accumulated distance of the cell divided by time. The y FMI of the cell was defined as the straight-line distance along the $y$ axis between the start position and the end position of cell divided by accumulated distance. For each experiment, 20 cells were randomly selected along each edge of the wound. Cells undergoing division, death or migration outside the field of the view were excluded from the analysis.

\section{Results}

Viability of MDA-MB-231 on ITO plate

The appropriate strength of electric field needed to be determined before electrotaxis experiment on ITO plate. Figure 3 shows the viability of MDA-MB-231 on direct- current electric field of ITO glass. The cells under the electric field of 0 or $1 \mathrm{~V} / \mathrm{cm}$ for 3 hours dyed red (Figure 3A and B). Most of cells under electric field of $2 \mathrm{~V} / \mathrm{cm}$ showed little green fluorescence or slightly red fluorescence, some of them emitted bright green fluorescence (Figure 3C).

\section{Electrotaxis of MDA-MB-231 on ITO plate}

To make the electrotaxis system more convenient than the established, we considered Indium-tin-oxide coated slide glass. To identify the function of ITO glass electrotaxis system, MDA-MB-231 were seeded on the ITO plate and electrotaxis was evaluated. We confirmed the electrotaxis of MDA-MB-231 on ITO plate under direct current electric fields of 0 and $1 \mathrm{~V} / \mathrm{cm}$. In the stimulation free condition, cells migrated randomly in all directions with a scattered distribution (Figure 4A). When $1 \mathrm{~V} / \mathrm{cm}$ of direct-current electric field was applied, MDA-MB-231 moved toward the anode (Figure 4B). To

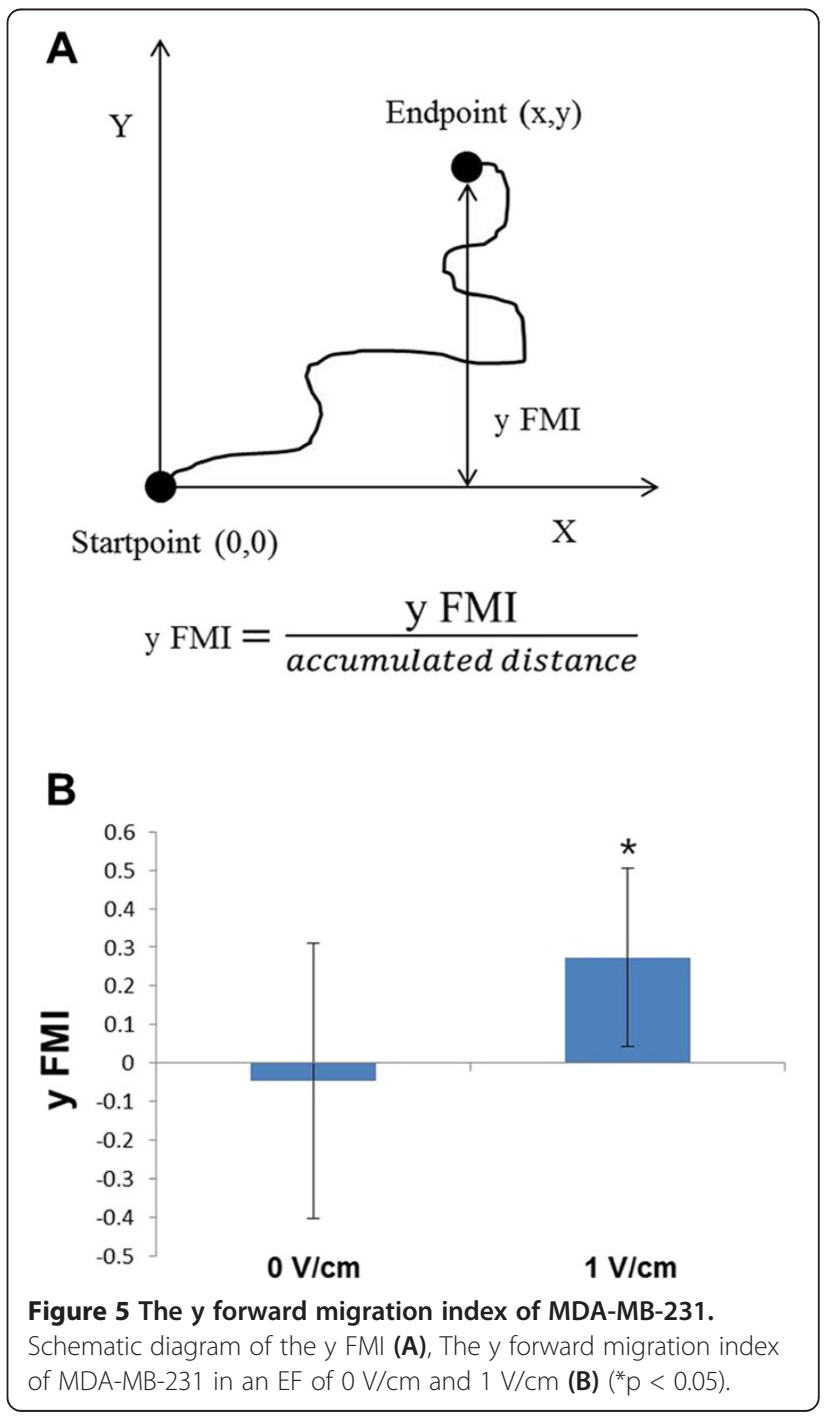




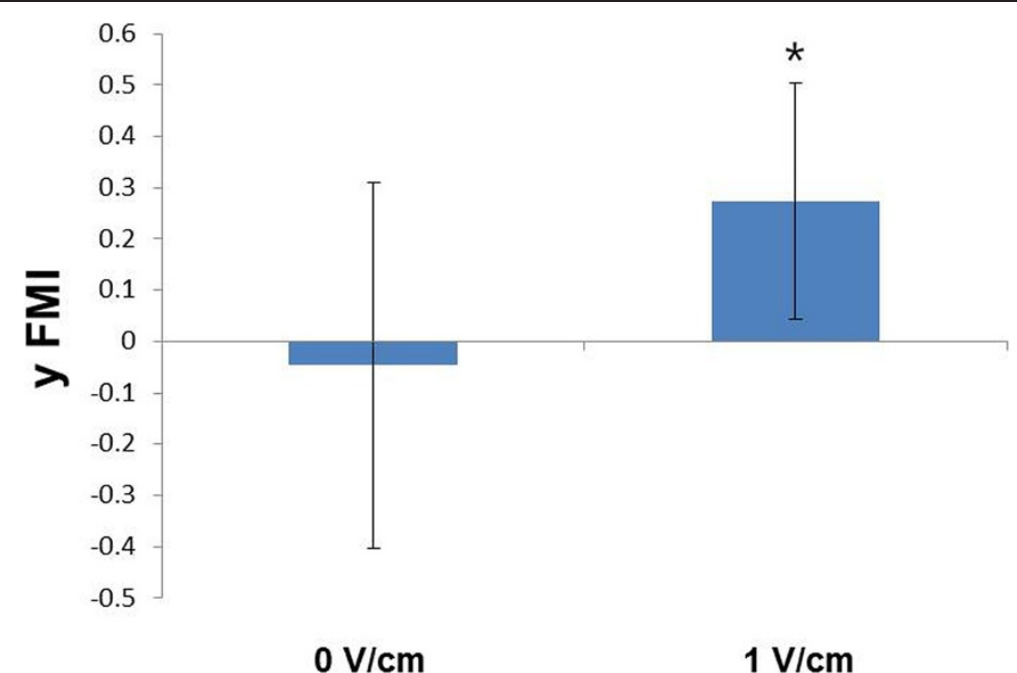

Figure 6 The migration speed of MDA-MB-231. The migration speed of MDA-MB-231 in an EF of $0 \mathrm{~V} / \mathrm{cm}$ and $1 \mathrm{~V} / \mathrm{cm}$.

characterize the latency in directional cell migration, we analyzed the $y$ forward migration index (y FMI) (Figure 5A). The y FMI value of 1 indicates the cell has migrated perfectly toward the anode, -1 means the cell has migrated perfectly toward the cathode and 0 indicates the cell has migrated perpendicular to the stimulation direction. The y FMI was $-0.046 \pm 0.357$ under the $0 \mathrm{~V} / \mathrm{cm}$ and was $0.273 \pm 0.231$ under dcEFs of $1 \mathrm{~V} / \mathrm{cm}$ (Figure $5 \mathrm{~B}$ ). However, there were no statistical differences between the migration speed of cells under $0 \mathrm{~V} / \mathrm{cm}$ $(36.99 \pm 9.40 \mu \mathrm{m} / \mathrm{hr})$ and $1 \mathrm{~V} / \mathrm{cm}(37.62 \pm 16.23 \mu \mathrm{m} / \mathrm{hr})$ (Figure 6).

\section{Discussion}

The LIVE/DEAD assay kit provides two-color fluorescence assay that distinguishes metabolically active cells from injured cells and dead cells. The assay is based on the reduction of C12-resazurin to red-fluorescent C12-resorufin in metabolically active cells and the uptake of the cell-impermeant, green-fluorescent nucleic acid stain, SYTOX Green dye, in cells with compromised plasma membranes (usually late apoptotic and necrotic cells). The dead cells emit mostly green fluorescence whereas the healthy, metabolically active cells emit mostly red fluorescence. The injured cells have lower metabolic activity and, consequently, reduced red fluorescence emission; because they possess intact membranes, however, injured cells accumulate little SYTOX Green dye and, therefore, emit very little green fluorescence [29-31]. The more damaged cells were observed when the higher strength of direct-current electric field was applied. We chose $1 \mathrm{~V} / \mathrm{cm}$ for the next experiment because most of cells were not damaged under $1 \mathrm{~V} / \mathrm{cm}$ condition.
In human keratinocytes, the directionality was increased under the direct-current electric field while the migration speed was decreased [32]. This indicates that there is a difference between established electrotaxis system and ITO glass electrotaxis system, because only directionality was increased under direct-current electric field of ITO glass while migration speed was not changed. The established electrotaxis system used agar-salt bridges to applied the direct-current electric field through the media. In a new electrotaxis system using ITO glass, however, the cells contacting to ITO glass can directly be affected by direct-current electric field. To explain the directional migration of MDA-MB-231 on directcurrent electric field of ITO glass and the differences between ITO glass system and existing electrotaxis system, further studies are required.

\section{Conclusions}

In conclusion, MDA-MB-231 on the ITO film coated glass in direct-current electric fields migrated toward anode. Cell viability was dependent on the strength of direct-current electric field. The migration speed of MDAMB-231 was not affected by the direct-current electric field using ITO plate. Therefore, the direct-current electric field using ITO glass induced the directional migration of breast cancer cell. Although further studies are required to figure out the differences between established electrotaxis and ITO glass electrotaxis system, it was identified that directcurrent electric field of ITO glass affected the directional migration of breast cancer cell.

\section{Availability of supporting data}

The data sets supporting the results of this article are included within the article. 


\section{Competing interests}

The authors declare that they have no competing interests.

\section{Authors' contributions}

MSK designed the experiments, carried out analysis of cell migration by direct-current electric field and drafted the manuscript. MHL participated in the design of the study and carried out the immunostaining. BK and HJS set up the real time observation system which is used in this study. MK and KEY participated in the acquisition of cell images. DK performed the statistical analysis and helped to interpret data. JP conceived of the study, and participated in its design and coordination and helped to draft the manuscript. All authors read and approved the final manuscript.

\section{Acknowledgement}

This research was supported by the National Research Foundation of Korea (NRF) funded by the Ministry of Science, ICT \& Future Planning (Grant No. 2005-2000117).

Received: 19 June 2014 Accepted: 9 July 2014

Published: 31 July 2014

\section{References}

1. Li S, Guan JL, Chien S: Biochemistry and biomechanics of cell mortility. Annu Rev Biomed Eng 2005, 7:105-150.

2. Lauffenburger DA, Horwitz AF: Cell migration: a physically integrated molecular process. Cell 1996, 84:359-369.

3. Al-Bazzaz FJ, Gailey C: Ion transport by sheep distal airways in a miniature chamber. Am J Physiol 2001, 281:1028-1034.

4. Dortch-Carnes J, Van Scott MR, Fedan J: Changes in smooth muscle tone during osmotic challenge in relation to epithelial bioelectric events in guinea pig isolated trachea. J Pharmacol Exp Ther 1999, 289:911-917.

5. Wang Q, Horisberger JD, Maillard M, Brunner HR, Burnier M: Salt- and angiotensin II-dependent variations in amiloride-sensitive rectal potential difference in mice. Clin Exp Pharmacol Physiol 2000, 27:60-66.

6. Szatkowski M, Mycielska M, Knowles R, Kho AL, Djamgoz MB: Electrophysiological recordings from the rat prostate gland in vitro: identified single-cell and transepithelial (lumen) potentials. BJU Int 2000, 86:1068-1075.

7. Sorensen E, Olesen J, Rask-Madsen J, Rask-Andersen H: The electrical potential difference and impedance between CSF and blood in unanesthetized man. Scand J Clin Lab Invest 1978, 38:203-207.

8. Sato MJ, Kuwayama H, Takayama ALK, Ueda M: Switching direction in electricsignal-induced cell migration by cyclic guanosine monophosphate and phosphatidylinositol signaling. Proc Natl Acad Sci U S A 2009, 106:6667-6672.

9. Li J, Nandagopal S, Wu D, Lin F: Activated T lymphocytes migrate toward the cathode of DC electric fields in microfluidic devices. Lab Chip 2011, 11:1298-1304

10. Robinson KR: The responses of cells to electrical fields: A review. J Cell Biol 1985, 101:2023-2027.

11. Nuccitelli R: A role for endogenous electric fields in wound healing. Curr Top Dev Biol 2003, 58:1-26.

12. Mycielska ME, Djamgoz MB: Cellular mechanisms of direct-current electric field effects: Galvanotaxis and metastatic disease. J Cell Sci 2004, 117:1631-1639.

13. McCaig CD, Rajnicek AM, Song B, Zhao M: Controlling cell behavior electrically: Current views and future potential. Physiol Rev 2005, 85:943-978.

14. Lin F: Lymphocyte electrotaxis in vitro and in vivo. J Immuno/ 2008, 181:2465-2471.

15. Weijtens CHL, Van Loon PAC: Influence of annealing on the optical properties of indium tin oxide. Thin Solid Films 1991, 196:1-10.

16. Nagatomo T, Maruta Y, Omoto O: Electrical and optical properties of vacuum-evaporated indium-tin oxide films with high electron mobility. Thin Solid Films 1990, 192:17-25.

17. Hamberg I, Granqvist CG: Evaporated Sn-doped In2O3 films: Basic optical properties and applications to energy-efficient windows. J Appl Phys 1986, 60:123-160.

18. Nishio K, Sei TI, Tsuchiya T: Preparation and electrical properties of ITO thin films by dip-coating process. J Mat Sci 1996, 31:1761-1766.
19. Djaoued $Y$, Phong VH, Badilescu S, Ashrit PV, Girouard FE, Truong V: Sol-gel-prepared ITO films for electrochromic systems. Thin Solid Films 1997, 293:108-112.

20. Mattox DM: Sol-gel derived, air-baked indium and tin oxide films. Thin Solid Films 1991, 204:25-32.

21. Faughnan BW, Crandall RS: Electrochromic displays based on $\mathbf{W O}_{3}$. Topics Applied Physics 1980, 40:181-211.

22. Meng L, Li C, Zhong G: The influence of the concentration of $\mathrm{Er}^{3+}$ ions on the characteristics of $\mathrm{AC}$-electroluminescence in $\mathrm{ZnS}: \mathrm{ErF}_{3}$ thin films. J Lumin 1987, 39:11-17.

23. Bellingham JR, Mackenzie AP, Phillips WA: Precise measurements of oxygen content: Oxygen vacancies in transparent conducting indium oxide films. Appl Phys Lett 1991, 58:2506-2508.

24. Valentini A, Quaranta F, Penza ME, Rizzi FR: The stability of zinc oxide electrodes fabricated by dual ion beam sputtering. J Appl Phys 1993, 73:1043-1045.

25. Ozasa K, Ye T, Aoyagi Y: Deposition of thin indium oxide film and its application to selective epitaxy for in situ processing. Thin Solid Film 1994, 246:58-64.

26. Luff BJ, Wilkinson JS, Perrone G: Indium tin oxide overlayered waveguides for sensor applications. Appl Opt 1997, 36:7066-7072.

27. Tamisier $L$, Caprani A: Electrochemical study of the $\mathrm{Fe}(\mathrm{CN})^{4-}{ }_{6} / \mathrm{Fe}(\mathrm{CN})^{3-}{ }_{6}$ couple at the ITO/NaCl interface. Electrochim Acta 1987, 32:1365-1369.

28. Alam MJ, Cameron DC: Optical and electrical properties of transparent conductive ITO thin films deposited by sol-gel process. Thin Solid Films 2000, 00:455-459.

29. Visser W, Scheffers WA, Vegte WHB, Dijken JP: Oxygen requirements of yeasts. Appl Environ Microbiol 1990, 56:3785-3792.

30. Reinheimer JA, Demkow MR: Comparison of rapid tests for assessing UHT milk sterility. J Dairy Res 1990, 57:239-243.

31. White MJ, DiCaprio MJ, Greenberg DA: Assessment of neuronal viability with Alamar blue in cortical and granule cell cultures. J Neurosci Methods 1996, 70:195-200

32. Yang HY, Charles RP, Hummler E, Baines DL, Isseroff RR: The epithelial sodium channel mediates the directionality of galvanotaxis in human keratinocytes. J Cell Sci 2013, 126:1942-1951.

doi:10.1186/2055-7124-18-10

Cite this article as: Kim et al:: Effects of direct current electric-field using ITO plate on breast cancer cell migration. Biomaterials Research 2014 18:10.

\section{Submit your next manuscript to BioMed Central and take full advantage of:}

- Convenient online submission

- Thorough peer review

- No space constraints or color figure charges

- Immediate publication on acceptance

- Inclusion in PubMed, CAS, Scopus and Google Scholar

- Research which is freely available for redistribution

Submit your manuscript at www.biomedcentral.com/submit
C Biomed Central 